\title{
THE EFFECT OF TOPICAL BETA-ADRENOCEPTOR BLOCKING AGENTS ON PULSATILE OCULAR BLOOD FLOW
}

\author{
C. D. MORSMAN, M. E. BOSEM, M. LUSKY and R. N. WEINREB \\ San Diego, California
}

\begin{abstract}
SUMMARY
Thirty-three ocular hypertensive patients $(21$ with primary open angle glaucoma and 12 glaucoma suspects) were randomly assigned to receive either timolol, levobunolol or betaxolol in one eye. Pulsatile ocular blood flow (POBF) was measured before treatment (baseline) and 2 hours after drop administration. After 1 week of regular twice-daily dosage, POBF was measured again both immediately before and 2 hours after drop instillation. All measurements were made by an investigator masked to treatment. POBF increased by $11 \%(p=0.09)$ at week 0 after levobunolol administration, and by $22 \%(p=0.20)$ at week 1 before drop administration compared with baseline. It dropped by $23 \%$ and $25 \%(p=0.04$ and 0.06 , respectively) before and after betaxolol administration at week 1. Although $P O B F$ was reduced in the timolol group, this change was not significant. These results can not be explained uniformly by changes in intraocular pressure or blood pressure. The relevance of these measurements to visual function in glaucoma is not known.
\end{abstract}

It is generally accepted that reducing intraocular pressure (IOP) can delay or prevent visual field loss in many patients with glaucoma. ${ }^{1}$ The most widely used ocular hypotensive drugs are topical betaadrenoceptor blockers, which lower IOP by reducing aqueous flow. These either act predominantly on beta-1 receptors, or are non-selective and act on both beta- 1 and beta- 2 receptors. The non-selective drugs are more effective ocular hypotensive agents than are beta- 1 selective drugs. ${ }^{2}$

It is becoming increasingly apparent that risk factors besides high IOP are associated with glaucoma. ${ }^{3}$ The relationships of some of these risk

From: Glaucoma Center and Research Laboratories, University of California, San Diego, California, USA.

Correspondence to: C. D. Morsman, FRCOphth, The North Hampshire Hospital, Department of Ophthalmology, Basingstoke RG24 9NA, UK. factors (e.g. hypertension, diabetes, peripheral vascular disease and vasospasm) to the vascular system suggest that blood flow in the optic nerve head and retina may be altered in glaucoma. ${ }^{4}$ Of the various vascular beds within the posterior segment, the choroidal circulation is of particular interest since it provides the major contribution to the blood flow of the optic nerve at the level of the lamina cribrosa. ${ }^{5}$

Beta-2 adrenergic receptors have been demonstrated in human optic nerve ${ }^{6}{ }^{6}$ as well as in choroidal and retinal blood vessels. ${ }^{7}$ Blockade of these receptors can cause vasoconstriction ${ }^{8}$ which could adversely affect visual function if adequate concentrations of the drug diffused into the posterior segment of the eye or were absorbed systemically. Although it is not possible to measure perfusion of the optic nerve directly or non-invasively, it has been suggested that pulsatile ocular blood flow (POBF) gives an indication by estimating choroidal flow. ${ }^{9-11}$

In this study, changes in POBF following instillation of two non-selective agents (timolol and levobunolol) and a beta-1 selective agent (betaxolol) were compared.

\section{SUBJECTS AND METHODS}

Thirty-three ocular hypertensive patients $(21$ with primary open angle glaucoma and 12 glaucoma suspects) were enrolled after their informed consent had been obtained. The mean age of the subjects was 64 years; there were 16 men and 17 women. All patients had at least two occasions. Glaucoma patients had characteristic visual field defects on the Octopus perimeter using programme G1 or 32, and glaucomatous disc cupping. Suspects had normal optic discs and visual fields. Patients were excluded if they had more than 5 dioptres of myopia, were diabetic or were using systemic vasoactive medications. All glaucoma treatment was discontinued for 2 weeks prior to the baseline measurement. 
At the first visit after the washout period (week 0), applanation tonometry was performed and the patient lay supine for 2 minutes. Brachial blood pressure and pulse rate were determined. The eyes were anaesthetised with topical proparacaine hydrochloride $0.5 \%$ (Ophthetic, Allergan) and POBF measured with the Langham system (Ocular Blood Flow Laboratories, Annapolis, MD) according to the technique described by Langham et al..$^{9,10}$ Four ocular pulse measurements of 5 seconds each were analysed for each eye. To reduce inter-observer bias, all measurements were recorded by the same operator, who was masked to both the treatment and the eye treated. The instrument was calibrated at the start of each session and verified against a silastic membrane at pressures of 15 and $40 \mathrm{mmHg}$ before each patient was tested.

The patients were randomly allocated to receive either $0.5 \%$ timolol maleate (Timoptic, MSD), $0.5 \%$ levobunolol hydrochloride (Betagan, Allergan) or $0.5 \%$ betaxolol hydrochloride (Betoptic, Alcon Laboratories). One drop of the drug was instilled by one of the investigators into the lower fornix of one eye selected at random and the nasolacrimal duct occluded for 2 minutes. All measurements were repeated 2 hours later. The patient was then asked to use the same drop in the same eye twice daily with nasolacrimal duct occlusion for 1 week. At that time (week 1) measurements were repeated again, before and 2 hours after the first drop administration of the day. To minimise the effect of diurnal variation, all measurements were taken between 0800 and 1000 hours.

To assess the reproducibility of POBF measurements, we had previously calculated the coefficient of variation (standard deviation/mean) of three repeated measurements on another 15 glaucoma subjects. ${ }^{12}$ The average coefficient of variation was $7.5 \%$ and this did not correlate with the magnitude of POBF.

Change in IOP, mean blood pressure and POBF were each compared with baseline (week 0 before drop instillation) using a paired $t$-test for normally distributed data or otherwise its non-parametric equivalent, the Wilcoxon signed rank test. Comparisons were done between treatment groups using the two-sample $t$-test or the Wilcoxon rank sum test, as appropriate. A $p$ value of $<0.05$ was considered significant.

\section{RESULTS}

There were no significant differences among patients allocated to each group in terms of age, gender or diagnosis.

\section{Intraocular Pressure}

All three drugs reduced IOP in the treated eye over
Table I. Intraocular pressure $(\mathrm{mmHg})$ in the treated eye at each visit before and after instillation of medicine

\begin{tabular}{lcclcc}
\hline & \multicolumn{2}{c}{ Week 0 } & & \multicolumn{2}{c}{ Week 1 } \\
\cline { 2 - 3 } \cline { 5 - 6 } & Before $^{\mathrm{a}}$ & After & & Before & After \\
\hline Timolol & 25 & $18(0.01)$ & & $19(0.01)$ & $19(0.03)$ \\
Levobunolol & 27 & $18(0.02)$ & & $17(0.01)$ & $17(0.01)$ \\
Betaxolol & 25 & $18(0.01)$ & & $20(0.02)$ & $17(0.01)$ \\
\hline
\end{tabular}

Figures in parentheses are $p$ values for the change from baseline. ${ }^{a}$ The baseline value.

Table II. Mean blood pressure $(\mathrm{mmHg})$ at each visit before and after instillation of medication

\begin{tabular}{lcclcc}
\hline & \multicolumn{2}{c}{ Week 0} & & \multicolumn{2}{c}{ Week 1 } \\
\cline { 2 - 3 } \cline { 6 - 7 } & Before $^{\text {a }}$ & After & & Before & After \\
\hline Timolol & 97 & 98 & & 95 & 96 \\
Levobunolol & 97 & 98 & & 98 & 96 \\
Betaxolol & 98 & 96 & & 100 & 97 \\
\hline
\end{tabular}

${ }^{\mathrm{a} B a s e l i n e ~ v a l u e .}$

Table III. Pulsatile ocular blood flow $(\mu \mathrm{l} / \mathrm{min})$ in the treated eye at each visit before and after instillation of medication

\begin{tabular}{lccccc}
\hline & \multicolumn{2}{c}{ Week 0 } & & \multicolumn{2}{c}{ Week 1 } \\
\cline { 2 - 3 } \cline { 5 - 6 } & Before $^{\mathrm{a}}$ & After & & Before & After \\
\hline Timolol & 498 & $467(0.84)$ & & $453(0.99)$ & $408(0.35)$ \\
Levobunolol & 492 & $546(0.09)$ & & $601(0.20)$ & $518(0.56)$ \\
Betaxolol & 483 & $520(0.42)$ & & $375(0.04)$ & $364(0.06)$ \\
\hline
\end{tabular}

Figures in brackets are $p$ values for the change from baseline.

${ }^{a}$ The baseline value.

the study period (Table I). This ocular hypotensive effect was slightly greater in the levobunolol group $(37 \%)$ compared with the betaxolol $(28 \%)$ or timolol $(24 \%)$ groups, though the differences were not statistically significant.

\section{Cardiovascular Parameters}

Mean blood pressure [diastolic + (systolic diastolic/3)] did not change by more than $2 \mathrm{mmHg}$ in any group (Table II), and there was no significant change in heart rate.

\section{Pulsatile Ocular Blood Flow}

Throughout the study period, there was a tendency for POBF to be increased in response to levobunolol and reduced in response to betaxolol. Significance $(p<0.05)$ or trends towards significance $(0.05<p<0.10)$ were seen for levobunolol at week $0(11 \%$ increase; $p=0.09$ ) and for betaxolol at week 1 before and after drop instillation $(23 \%$ and $25 \%$ reduction; $p=0.04$ and 0.06 , respectively) compared with baseline (Table III). The difference in POBF between these two drugs was highly significant $(p<0.01)$ at week 1 both before and after drop instillation. There was no statistically significant effect on POBF in response to timolol. 


\section{Correlations}

The changes in POBF and IOP were inversely correlated in the treated eye at week 1 before instillation $(r=-0.39)$. There were no other significant correlations between observed changes in POBF and other parameters.

\section{DISCUSSION}

In this study, levobunolol increased POBF by $11 \%$ after a single dose $(p=0.09)$. This confirms our previous results in which levobunolol was found to increase POBF by $13 \%$ in 14 primary open angle glaucoma patients. ${ }^{12}$ In addition, we observed a decrease in POBF in response to betaxolol following 1 week of treatment. There was no significant response to timolol.

Several techniques for measuring blood flow noninvasively in human eyes have been proposed. The instrument used in our study measures pulsatile ocular flow. The ocular phase (IOP vs time) is recorded with a pneumatonometer. A pressurevolume relationship for the human eye $\mathrm{e}^{13}$ is then used to derive ocular volume changes. ${ }^{9,10}$ Finally, POBF is determined by calculating the change in ocular volume over time.

Practical and theoretical difficulties are encountered in performing and interpreting POBF measurements with the Langham system. The reliability and reproducibility of the techniques are limited and the instrument needs to be calibrated before each examination session to give comparable readings. In equating POBF with choroidal blood flow, several assumptions are made. First, it is assumed that the majority of ocular blood flow is choroidal. In the monkey, the choroid accounts for over $90 \%$ of ocular blood flow. ${ }^{14}$ Second, it is assumed that ocular blood flow is predominantly pulsatile. Although diastolic blood velocity in the ophthalmic artery is minimal, ${ }^{15}$ it is not known how diastolic blood velocity corresponds to non-pulsatile flow. Because the instrument we used measures only pulsatile flow, it is not possible to recognise changes in the nonpulsatile component. Third, it is assumed that the pressure-volume relationship used by the instrument

Table IV. Results of previous studies on ocular blood flow response to topical beta-adrenoceptor (percentage change)

\begin{tabular}{|c|c|c|c|}
\hline & Betaxolol & Levobunolol & Timolol \\
\hline $\begin{array}{l}\text { Single-dose studies } \\
\text { Bosem } \text { et al. } .^{12} \\
\text { Grajewski et al. } \\
\text { Yamazaki } \text { et al. }{ }^{17} \\
\text { Yoshida et al. }{ }^{18}\end{array}$ & & +13 & $\begin{array}{l}\text { NS } \\
\text { NS } \\
-32\end{array}$ \\
\hline $\begin{array}{l}\text { One week or more of tr } \\
\text { Bucci et al. } .^{20} \\
\text { Morsman (this study) } \\
\text { Trew and Smith }{ }^{19} \\
\text { Boles Carenini } \text { et al. }\end{array}$ & $\begin{array}{c}\text { atment } \\
\text { NS } \\
-22 \\
+24\end{array}$ & $\begin{array}{l}+7 \\
+11 \\
-18\end{array}$ & $\begin{array}{l}\text { NS } \\
\text { NS } \\
\text { NS } \\
\text { NS }\end{array}$ \\
\hline
\end{tabular}

NS, no significant change. to calculate ocular volume is valid for all eyes. However, this relationship was developed from data on only three enucleated and six living eyes. ${ }^{9,13}$ Differences in scleral rigidity, eye volume, and axial length could each affect the derived relationship and, hence, the calculation of ocular blood volume and flow. For example, the accuracy of the technique has been questioned in individuals with high myopia, who are known to have low scleral rigidity and a high axial length. ${ }^{16}$

In addition to our previous report, ${ }^{12}$ several other studies have looked at changes in pulsatile flow over a few hours after instillation of non-selective topical beta adrenoceptor blocking drugs (Table IV). The results of Yamazaki et al. ${ }^{17}$ support our finding of no effect on POBF with timolol. In contrast, Yoshida et $a^{18}$ found a $30 \%$ reduction in POBF in a small number of normal individuals 90 minutes after the instillation of timolol. Grajewski et al. $^{7}$ measured pulse amplitude with the same instrument before and 2 hours after timolol administration. They found a decrease with oral but not with topical instillation. After a 2 week treatment period, Trew and Smith ${ }^{19}$ found no change in POBF with timolol in most of their glaucoma patients. Bucci et $a .^{20}$ measured ocular pulse amplitude with an earlier version of the Langham system, but did not make a correction for amplitude change due to IOP lowering. After 2 weeks of treatment they found that levobunolol increased POBF; timolol and betaxolol caused no change. Most recently, Boles Carenini et al. $^{21}$ noted that after 1 month of treatment POBF was decreased with timolol (not significantly) and levobunolol (significantly) but increased with betaxolol (significantly). The differences among these three groups can be accounted for by differences in pre-treatment POBF; after treatment POBF was remarkably similar. The sample size in the levobunolol group was unsatisfactory with only 4 patients being tested.

These previous studies may not be strictly comparable to the present one, as steps to minimise systemic absorption of drug do not appear to have been taken. In our study, all patients were carefully instructed on the technique of nasolacrimal duct occlusion, and on the day of testing this was supervised by one of the investigators. The lack of change in blood pressure and pulse demonstrates the effectiveness of this procedure. It is unlikely that changes we observed in POBF were due to systemic absorption of the drugs; they are more likely to be due to reduced IOP or diffusion of drug into the posterior segment.

Although the drugs tested are similar in many respects, pharmacokinetic differences among them might be responsible for the results we obtained. Although both timolol and levobunolol are nonselective beta-adrenergic blocking agents with 
comparable ocular hypotensive actions, their rates of uptake and diffusion may not be the same. After topical administration, levobunolol is transformed in the aqueous into a more polar metabolite, dihydrolevobunolol, ${ }^{22}$ which may diffuse more slowly into the posterior segment than timolol. This would cause less vasoconstriction and preserve POBF.

Another possible explanation for the differences in POBF between two non-selective agents is differing effects on vascular tone. This could alter the proportion of pulsatile and non-pulsatile flow without affecting the total.

We observed higher POBF in subjects treated with non-selective beta-blockers than with a beta-1 selective agent. After 1 week of treatment there was a significant difference in POBF both before and after drop administration between levobunolol and betaxolol. The increase in POBF after administration of levobunolol could be related to the amount of IOP reduction $(37 \%)$, as perfusion pressure (mean $\mathrm{BP}-\mathrm{IOP}$, where $\mathrm{BP}$ is blood pressure) is increased in the absence of vasoconstriction. In support of this, we found that POBF and IOP were inversely correlated after 1 week of treatment before drop administration. This factor alone cannot account for the reduction of POBF seen in the betaxolol group, however. As mentioned above, POBF differences between levobunolol and betaxolol might also be due to changes in the proportion of pulsatile and nonpulsatile blood flow.

The relevance of POBF to the preservation of vision in glaucoma is not fully understood. Optic nerve blood flow is presumably dependent upon both pulsatile and non-pulsatile flow. Although it is often assumed that a higher total blood flow is beneficial, if there were large regional variations then any susceptible tissue, including the optic nerve head, might still be at risk. Even though retinal blood flow is a small component of total ocular blood flow, it may be equally or more important than choroidal flow because of the need to maintain the perfusion of the retinal ganglion cells. Treatment for glaucoma which increases choroidal, retinal and optic nerve blood flow may be desirable, particularly if it lowers IOP concomitantly.

Mr Morsman was supported by the Oxford Congress Scholarship and the T.F.C. Frost Charitable Trust.

Key words: Beta blockers, Glaucoma, Ocular blood flow.

\section{REFERENCES}

1. Odberg T. Visual field prognosis in advanced glaucoma. Acta Ophthalmol 1987;Suppl 182:27-9.

2. Vogel R, Tipping R, Kulaga SF, Clineschmidt CM. Changing therapy from timolol to betaxolol: effect on intraocular pressure in selected patients with glaucoma. Arch Ophthalmol 1989;107:1303-7.

3. Van Buskirk EM, Cioffi GA. Glaucomatous optic neuropathy. Am J Ophthalmol 1992;113:447-52.

4. Weinreb RN. Why study the microcirculation in glaucoma? J Glaucoma 1992;1:145-7.

5. Alm A, Bill A. Ocular circulation. In: Moses RA, Hart WM, editors. Adler's physiology of the eye: clinical application, vol. 8. St Louis: CV Mosby, 1987:193-203.

6. Dawidek GMB, Robinson MI. Beta-adrenergic receptors in human anterior optic nerve: an autoradiographic study. Eye 1993;7:122-6.

7. Grajewski AL, Ferrari-dileo G, Feuer WJ, Anderson DR. Beta-adrenergic-responsiveness of choroidal vasculature. Ophthalmology 1991;98:989-95.

8. Van Buskirk EM, Bacon DR, Fahrenbach WH. Ciliary vasoconstriction after topical adrenergic drugs. Am J Ophthalmol 1990;109:511.

9. Langham ME. Ocular blood flow and visual loss in glaucomatous eyes. In: Kreiglestein GK, editor. Glaucoma update III. Heidelberg: Springer-Verlag, 1987:58-66.

10. Silver DM, Farrell RA, Langham ME, et al. Estimation of pulsatile ocular blood flow from intraocular pressure. Acta Ophthalmol 1989;Suppl 191:25-9.

11. Krakow CE. Calculation of the pulsatile ocular blood flow. Invest Ophthalmol Vis Sci 1992;33:2754-6.

12. Bosem ME, Lusky M, Weinreb RN. Short term effects of levobunolol on ocular pulsatile blood flow. Am J Ophthalmol 1992;114:280-6.

13. Eisenlohr J, Langham ME, Maumenee AE. Manometric studies of the pressure/volume relation in living and enucleated eyes of individual subjects. $\mathrm{Br} \mathbf{J}$ Ophthalmol 1962;46:536-48.

14. Alm A, Bill A. Ocular and optic nerve flow at normal and increased intraocular pressure in monkeys (Macaca irus): a study with radioactive labelled microspheres including flow determination in brain and some other tissues. Exp Eye Res 1973;15:15.

15. Michelson G, Gierth K, Priem R, Laumer R. Blood velocity in the ophthalmic artery normal subjects and patients with endophthalmitis. Invest Ophthalmol Vis Sci 1990;3:1919.

16. James CB, Trew DR, Clark K, Smith SE. Factors influencing the ocular pulse-axial length. Graefes Arch Clin Exp Ophthalmol 1991;229:341.

17. Yamazaki S, Baba H, Tokoro T. Effects of timolol and carteolol on ocular pulsatile blood flow. Acta Soc Ophthalmol Jpn 1992;96:973-7.

18. Yoshida A, Feke GT, Ogasawara H, et al. Effect of timolol on human retinal, choroidal and optic nerve head circulation. Ophthalmic Res 1991;23:162-70.

19. Trew DR, Smith SE. Postural studies in pulsatile ocular blood flow. II. Chronic open angle glaucoma. $\mathrm{Br} \mathrm{J}$ Ophthalmol 1991; 75:71-5.

20. Bucci MG, Pescosolido N, Mariotti SP, Lentini FM. Comportamento dell'ampiezza del polso oculare dopo instillazione di beta-bloccanti. Boll Ocul 1990;69:28597.

21. Boles Carenini B, Brogliatti B, Boles Carenini A. Pulsatile ocular blood flow and antiglaucomatous drugs. New Trends Ophthalmol 1992;7:195-200.

22. Di Carlo FJ, Leinweber FJ, Szpiech JM, Davidson WF. Metabolism of 1-bunolol. Clin Pharmacol Ther 1977;22:858. 